\title{
Profil Pasien Pasca Kraniotomi di ICU RSUP Prof. Dr. R. D. Kandou Manado Periode Juli 2016 - Juni 2017
}

\author{
${ }^{1}$ Celine Tanriono \\ ${ }^{2}$ Diana C. Lalenoh \\ ${ }^{2}$ Mordekhai L. Laihad
}

\author{
${ }^{1}$ Program Studi Pendidikan Dokter Fakultas Kedokteran Universitas Sam Ratulangi Manado \\ ${ }^{2}$ Bagian Anestesiologi dan Terapi Intensif FK Unsrat/RSUP Prof. Dr. R. D. Kandou Manado \\ Email: tanriono.celine@gmail.com
}

\begin{abstract}
Craniotomy is a surgical action by opening the skull bone to provide direct access to the brain. Craniotomy can be performed in patients suffering from brain tumors, cerebral hemorrhage, cerebral aneurysms, cerebral infection, and brain trauma. This study was aimed to obtain the profile of post craniotomy patients at ICU Prof. Dr. R. D. Kandou Hospital Manado from July 2016 to June 2017. This was a descriptive retrospective study using medical record data of post craniotomy patients at Prof. Dr. R. D. Kandou Manado. There were 30 post craniotomy patients at the ICU. The majority of them had traumatic brain injury as the underlying disease (77\%), males (90\%), and aged 15-24 years old (37\%). Many post craniotomy patients used mechanical ventilators $(80 \%)$ with prolonged use $>72$ hours $(46 \%)$. The average lengh of post craniotomy care in ICU was 2 days (27\%). Eleven patients (36\%) died at $>72$ hours treated in ICU and caused by sepsis (55\%). The average Glasgow coma scale preoperative was 8-12 (57\%) and the physical status according to the American society of Anesthesiologist (ASA) was III E (67\%). Conclusion: Most post craniotomy patients were 15-24 years old, male, traumatic brain injury as the underlying disease of craniotomy, duration in ICU 2 days. A part of the patients died due to sepsis. Many post craniotomy patients used mechanical ventilators $>72$ hours. The majority had preoperative Glasgow coma scale of 8-12 and the highest ASA physical status were III E.
\end{abstract}

Keywords: craniotomy, ventilator, traumatic brain injury, mortality

\begin{abstract}
Abstrak: Kraniotomi adalah tindakan pembedahan dengan membuka tulang tengkorak untuk memberikan akses secara langsung ke otak. Kraniotomi dapat dilakukan pada pasien yang menderita tumor otak, perdarahan otak, aneurisma serebri, infeksi otak, serta trauma otak. Penelitian ini bertujuan untuk mengetahui profil pasien pasca kraniotomi di ICU RSUP Prof. Dr. R. D. Kandou Manado periode Juli 2016 - Juni 2017. Jenis penelitian ialah deskriptif retrospektif, menggunakan data rekam medik pasien pasca kraniotomi di RSUP Prof. Dr. R. D. Kandou Manado. Hasil mendapatkan 30 orang pasca kraniotomi di ICU dengan penyakit yang mendasari terbanyak ialah cedera kepala (77\%), jenis kelamin laki-laki (90\%), dan usia 15-24 tahun (37\%). Pasien pasca kraniotomi banyak yang menggunakan ventilator mekanik (80\%) dengan lama penggunaan $>72$ jam (46\%). Lama perawatan pasca kraniotomi di ICU rata-rata 2 hari (27\%), 11 orang meninggal dunia (36\%) pada $>72$ jam di rawat di ICU yang disebabkan oleh sepsis (55\%). Rerata Glasgow Coma Scale preoperatif 8-12 (57 \%) dan status fisik menurut American Society of Anesthesiologist (ASA) terbanyak III E (67\%). Simpulan: Pasien pasca kraniotomi terbanyak pada usia 15-24 tahun, jenis kelamin laki-laki, penyakit mendasari kraniotomi ialah cedera kepala, dan lama rawat ICU 2 hari. Sebagian meninggal dengan penyebab utama sepsis. Pasien pasca kraniotomi banyak yang menggunakan ventilator mekanik dengan lama penggunaan $>72 \mathrm{jam}$. Glasgow Coma Scale preoperatif terbanyak pada 8-12 dan status fisik ASA terbanyak yaitu III E.
\end{abstract}

Kata kunci: kraniotomi, ventilator, cedera kepala, mortalitas 
Kraniotomi adalah tindakan pembedahan dengan membuka tulang tengkorak untuk memberikan akses secara langsung ke otak. ${ }^{1}$ Jumlah pasien pasca kraniotomi yang dirawat di Intensif Care Unit (ICU) masih cukup banyak. Hanak et al. ${ }^{2}$ melaporkan bahwa 400 orang (92\%) dirawat di ICU dari 432 pasien yang dilakukan tindakan kraniotomi. $^{2}$

Kraniotomi dapat dilakukan pada tumor otak, perdarahan otak seperti subdural hematoma, epidural hematoma, aneurisma serebri, malformasi arteriovenous, infeksi otak seperti abses serebri serta trauma otak. ${ }^{3}$ Buang dan Haspani mendapatkan bahwa kasus kraniotomi terbanyak dilakukan pada pasien trauma sebanyak $40 \%$ di rumah sakit di Kuala Lumpur. ${ }^{4}$

Jasa et al. ${ }^{5}$ melaporkan bahwa angka kematian pasien pasca kraniotomi sebanyak $57 \%$ setelah 5 hari dirawat di ICU yang disebabkan oleh sepsis. Angka kematian pasca kraniotomi dipengaruhi oleh beberapa hal seperti diagnosis penyakit yang menjadi indikasi dilakukannya kraniotomi, komplikasi pasca operatif dan faktor medis lainnya. $^{6}$

Penelitian ini bertujuan untuk mendapatkan profil pasien pasca kraniotomi di ICU RSUP Prof. Dr. R. D. Kandou Manado periode Juli 2016 sampai Juni 2017.

\section{METODE PENELITIAN}

Jenis penelitian ini ialah deskriptif retrospektif dengan metode pengambilan sampel non probability sampling yaitu purposive sampling. Tempat penelitian di Intalasi Rekam Medik RSUP Prof. R. D. Kandou dengan jangka waktu 3 bulan yaitu September - Desember. Subjek penelitian ialah semua pasien pasca kraniotomi yang di rawat di ICU RSUP. Prof. R. D. Kandou periode Juli 2016 - Juni 2017.

\section{HASIL DAN BAHASAN}

Jumlah pasien pasca kraniotomi di ICU RSUP Prof. R. D. Kandou Manado periode Juli 2016 - Juni 2017 sebanyak 30 kasus. Pada Tabel 1 didapatkan pasien pasca kraniotomi terbanyak pada usia 15-24 tahun yaitu 11 orang (37\%) dengan jenis kelamin laki-laki 27 kasus (90\%).

Tabel 1. Distribusi jumlah dan persentase pasien pasca kraniotomi berdasarkan data dermografis

\begin{tabular}{ccc}
\hline Variabel & $\mathbf{N}$ & $\mathbf{\%}$ \\
\hline Usia & & \\
0-14 tahun & 2 & 7 \\
15-24 tahun & 11 & 37 \\
25-34 tahun & 3 & 10 \\
35-44 tahun & 3 & 10 \\
45-64 tahun & 8 & 26 \\
?65 tahun & 3 & 10 \\
Jumlah & 30 & 100 \\
Jenis kelamin & & \\
Laki-laki & 27 & 90 \\
Perempuan & 3 & 10 \\
Jumlah & 30 & 100 \\
\hline
\end{tabular}

Berdasarkan Tabel 2, diagnosis penyakit terbanyak pada cedera kepala sebanyak 23 kasus (77\%), dimana terbanyak ialah EDH (40\%). Buang dan Haspani ${ }^{4}$ menyatakan bahwa kasus kraniotomi terbanyak dilakukan pada trauma yaitu $36,9 \%$ dan lebih banyak terjadi pada lakilaki sebanyak 69,5\%. ${ }^{4}$ Hal ini berkaitan dengan tingginya angka kecelakaan kendaraan bermotor yang paling banyak melibatkan laki-laki dan sering pada usia remaja. Menurut Riset Kesehatan Dasar 2013, kecelakaan kendaraan bermotor paling sering terjadi pada laki-laki $(44,6 \%)$ dengan kelompok usia paling sering terjadinya kecelakaan ialah 15-24 tahun $(64,7 \%)^{7}$

Tabel 2. Distribusi jumlah dan persentase pasien pasca kraniotomi

\begin{tabular}{lrrrr}
\hline \multicolumn{1}{c}{ Variabel } & \multicolumn{1}{c}{ N } & \multicolumn{2}{c}{$\%$} \\
\hline Diagnosis penyakit & & & & \\
Cedera kepala & 23 & & & 77 \\
Epidural hematoma & & 12 & 40 & \\
$\quad$ Subdural hematoma & & 10 & 33 & \\
Intraserebral hematoma & & 8 & 27 & \\
Stroke Hemoragik & 7 & & & 23 \\
$\quad$ Jumlah & $\mathbf{3 0}$ & & & $\mathbf{1 0 0}$ \\
Kematian pasien & & & & \\
$\quad$ 24-48 jam & 2 & \multicolumn{2}{c}{18} \\
\hline
\end{tabular}




\begin{tabular}{ccc}
\hline 48-72 jam & 3 & 27 \\
$>$ 72 jam & 6 & 55 \\
Jumlah & $\mathbf{1 1}$ & $\mathbf{1 0 0}$ \\
Penyebab kematian & & \\
Sepsis & 6 & 55 \\
Pneumonia & 1 & 9 \\
Herniasi serebri & 3 & 27 \\
Gagal napas & 1 & 9 \\
Jumlah & $\mathbf{1 1}$ & $\mathbf{1 0 0}$ \\
Penggunaan ventilator mekanik & \\
Ya & 24 & 80 \\
Tidak & 6 & 20 \\
Jumlah & $\mathbf{3 0}$ & $\mathbf{1 0 0}$ \\
Lama penggunaan ventilator mekanik \\
< 24 jam & 2 & 8 \\
24-48 jam & 5 & 21 \\
48-72 jam & 6 & 25 \\
$>$ 72 jam & 11 & 46 \\
Jumlah & $\mathbf{2 4}$ & $\mathbf{1 0 0}$ \\
Lama rawat ICU & & \\
1 hari & 0 & 0 \\
2 hari & 8 & 27 \\
3 hari & 4 & 13 \\
4 hari & 2 & 7 \\
5 hari & 4 & 13 \\
6 hari & 1 & 3 \\
7 - 14 hari & 6 & 20 \\
$>$ 14 hari & 5 & 17 \\
Jumlah & $\mathbf{3 0}$ & $\mathbf{1 0 0}$ \\
\hline
\end{tabular}

Tabel 3. Distribusi jumlah dan persentase pasien pasca kraniotomi (lanjutan)

\begin{tabular}{ccc}
\hline Variabel & $\mathbf{N}$ & $\mathbf{\%}$ \\
\hline Glasgow Coma Scale preoperatif & \\
GCS < 8 & 10 & 33 \\
GCS 8-12 & 17 & 57 \\
GCS 13-15 & 3 & 10 \\
Jumlah & $\mathbf{3 0}$ & $\mathbf{1 0 0}$ \\
Status fisik American society of & \\
Anesthesiologist (ASA) & & \\
I E & 0 & 0 \\
II E & 2 & 6 \\
III E & 20 & 67 \\
IV E & 8 & 27 \\
V E & 0 & 0 \\
Jumlah & $\mathbf{3 0}$ & $\mathbf{1 0 0}$ \\
\hline
\end{tabular}

Dari 30 orang yang dilakukan tindakan kraniotomi, 11 orang diantaranya meninggal dunia pada rata-rata $>72$ jam setelah dirawat di ICU. Jasa et al. $^{5}$ mendapatkan bahwa angka kematian pasca kraniotomi pada cedera kepala sebanyak $57 \%$ setelah $>72$ jam di rawat di ICU dimana penyebab paling sering adalah sepsis. Kematian ini diakibatkan karena adanya penyakit penyerta lainnya seperti syok sepsis, pneumonia, herniasi serebri serta gagal napas. Pada penelitian ini penyebab terbanyak ialah sepsis $(55 \%)$. Pribadi ${ }^{8}$ mendapatkan penyebab kematian pasien pasca kraniotomi di RS Kariadi Semarang yang terbanyak ialah syok sepsis sebesar 33,3\%.

Pasien pasca kraniotomi banyak yang menggunakan ventilator mekanik yaitu sebanyak 24 orang (80\%) dengan lama penggunaan $>72$ jam yaitu sebanyak 11 orang $(46 \%)$. Sodiq et al. ${ }^{9}$ menyatakan pasien pasca kraniotomi lebih sering menggunakan ventilator mekanik yaitu sebesar $66 \%$ dengan lama penggunaan ventilator paling banyak pada 1 hari (79\%). Hal ini dikarenakan pasien pasca kraniotomi memiliki penurunan potency airway sehingga membutuhkan penggunaan venti-lator. Selain itu juga, penggunaan ventilator digunakan untuk menginduksi hipokapnea sehingga $\mathrm{PaCO}_{2}$ berada dalam kisaran normal. $^{10,11}$

Lama rawat di ICU pasien pasca kraniotomi paling banyak pada 2 hari yaitu sebanyak 8 orang $(26,7 \%)$. Sodiq et al. ${ }^{9}$ menyatakan bahwa lama rawat di ICU paling banyak pada 2 hari yaitu $40 \%$.

Glasgow Coma Scale (GCS) preoperatif terbanyak yaitu GCS 8-12 sebanyak 17 orang $(56,7 \%)$. Zwingly et al. ${ }^{12}$ mendapatkan GCS preoperatif pasien cede-ra kepala terbanyak pada 9-13 yaitu 74,2 \%. Hal ini dikarenakan kebanyakan pasien yang akan dilakukan kraniotomi datang dengan mengalami penurunan kesadaran. Dari penelitian ini, terdapat 3 orang pasca kraniotomi yang dirawat di ICU dengan GCS preoperatif 13-15. Hal ini dikarenakan adanya penyulit perioperatif yang dialami alami pasien seperti kejang, chronic kidney disease (CKD), hipertensi, elektrolit imbalance, peningkatan tekanan intrakranial, serta adanya gambaran EKG yang abnormal (Tabel 3). Selain itu, pasien tersebut membutuhkan penggunaan venti- 
lator sehingga perlu untuk dilakukan perawatan intensif. Operasi yang lama juga dapat menyebabkan komplikasi pasca operatif seperti edema serebri. ${ }^{9}$ Pada penelitian ini, lama operasi pasien kraniotomi dengan GCS preoperatif 13-15 rata-rata $>3$ jam.

Semua pasien pasca kraniotomi yang di rawat di ICU melakukan operasi emergency dengan skor ASA terbanyak yaitu III sebanyak 20 orang $(66,7 \%)$. Buang dan Haspani $^{4}$ mendapatkan bahwa operasi neurosurgical terbanyak pada tipe operasi emergency yaitu sebesar $63,1 \%$. Adigun et al. ${ }^{13}$ menyatakan bahwa skor ASA pasien yang dilakukan kraniotomi terbanyak pada ASA III yaitu sebanyak $56 \%$.

Tabel 3. Distribusi diagnosis penyakit, lama operasi dan penyulit pasien pasca kraniotomi berdasarkan Glasgow Coma Scale preoperative

\begin{tabular}{|c|c|c|c|c|c|c|c|c|c|}
\hline \multirow{3}{*}{\multicolumn{2}{|c|}{ Variabel }} & \multicolumn{6}{|c|}{$\begin{array}{c}\text { Glasgow Coma scale } \\
\text { Preoperatif }\end{array}$} & \multirow{2}{*}{\multicolumn{2}{|c|}{ Jumlah }} \\
\hline & & \multicolumn{2}{|c|}{$<8$} & \multicolumn{2}{|c|}{$8-12$} & \multicolumn{2}{|c|}{$13-15$} & & \\
\hline & & $\mathrm{N}$ & $\%$ & $\mathrm{~N}$ & $\%$ & $\mathrm{~N}$ & $\%$ & $\mathrm{~N}$ & $\%$ \\
\hline \multicolumn{10}{|c|}{ Diagnosis penyakit } \\
\hline & $\mathrm{EDH}$ & 6 & 50 & 5 & 42 & 1 & 8 & 12 & 32 \\
\hline \multirow[t]{2}{*}{ Cedera kepala } & SDH & 3 & 30 & 6 & 60 & 1 & 10 & 10 & 27 \\
\hline & $\mathrm{ICH}$ & 2 & 25 & 6 & 75 & - & - & 8 & 22 \\
\hline $\begin{array}{c}\text { Stroke } \\
\text { Hemoragik }\end{array}$ & & 2 & 29 & 4 & 57 & 1 & 14 & 7 & 19 \\
\hline Jumlah & & & & & & & & & 100 \\
\hline \multicolumn{10}{|l|}{ Lama operasi } \\
\hline$<1$ jam & & - & - & 2 & 100 & - & - & 2 & 7 \\
\hline $1-2$ jam & & 4 & 50 & 4 & 50 & - & - & 8 & 27 \\
\hline $2-3$ jam & & 5 & 38.5 & 8 & 61.5 & - & - & 13 & 43 \\
\hline$>3$ jam & & 1 & 14 & 3 & 43 & 3 & 43 & 7 & 23 \\
\hline Jumlah & & & & & & & & 30 & 100 \\
\hline
\end{tabular}

Penyulit

\begin{tabular}{ccccccccc} 
Peningkatan TIK & 3 & 17 & 13 & 72 & 2 & 11 & 18 & 60 \\
Sepsis & 3 & 43 & 4 & 57 & - & - & 7 & 23 \\
Pneumonia & 1 & 20 & 4 & 80 & - & - & 5 & 17 \\
EKG abnormal & 5 & 33 & 9 & 60 & 1 & 7 & 15 & 50 \\
Elektrolit imbalance & 3 & 33 & 5 & 56 & 1 & 11 & 9 & 30 \\
Hipertensi & 1 & 14 & 5 & 72 & 1 & 14 & 7 & 23 \\
Diabetes Melitus & 2 & 40 & 3 & 60 & - & - & 5 & 17 \\
Acute Kidney Injury & 1 & 25 & 3 & 75 & - & - & 4 & 13 \\
Chronic kidney Disease & - & - & - & - & 1 & 100 & 1 & 3 \\
Kejang & - & - & - & - & 1 & 100 & 1 & 3 \\
Tidak ada data & 2 & 67 & 1 & 33 & - & - & 3 & 10 \\
\hline
\end{tabular}

$\mathrm{EDH}=$ Epidural Hematoma

$\mathrm{SDH}=$ Subdural Hematoma

$\mathrm{ICH}=$ Intraserebral Hematoma 


\section{SIMPULAN}

Dari hasil penelitian ini dapat disimpulkan bahwa pasien pasca kraniotomi yang dirawat di ICU RSUP Prof. R. D. Kandou Manado periode Juli 2016 - Juni 2017 yang terbanyak ialah jenis kelamin laki-laki, usia 15-24 tahun, penyakit yang mendasari kraniotomi ialah cedera kepala, menggunakan ventilator mekanik dengan lama penggunaan $>72$ jam, lama perawatan pasca kraniotomi di ICU rata-rata 2 hari. Sebagian pasien meninggal dan disebabkan oleh sepsis. Glasgow Coma Scale preoperatif pasien kraniotomi rata-rata 8-12 dan status fisik ASA terbanyak III E.

\section{SARAN}

Disarankan untuk melakukan penelitian lanjut yang mencari hubungan antar variabel yang diteliti dengan pasien pasca kraniotomi serta komplikasi yang terjadi pasca operatif.

Perlu ada perbaikan dan peningkatan dalam pengelolaan data pasien dalam hal kelengkapan data dan kerapian penyimpanan data rekam medik di Instalasi Rekam Medik RSUP Prof. Dr. R. D. Kandou Manado untuk menunjang penelitian yang lebih akurat.

\section{DAFTAR PUSTAKA}

1. Garrett MP, Spetzler RF. Craniotomy. In: Encyclopedia of Neurological Science (2nd ed). USA: Elsevier, 2014: p. 896-7.

2. Hanak BW, Walcott BP, Nahed BV, Muzikansky A, Mian MK, Kimberly WT, et al. Post operative intensive care unit requirements following elective craniotomy. World Neurosurg. 2014; 81(1):65-72.

3. Luc J, Ray T. Craniotomy. University of Rochester Medical Center. New York. 2017. [cited 2017 Jun 23]. Available from: https://www.urmc. rochester. edu/encyclopedia/content.aspx? contenttypeid $=92 \&$ contentid $=\mathrm{P} 08767$.

4. Buang SS, Haspani MS. Risk factors for neurosurgical site infections after a neurosurgical procedur: a prospective observational study at Hospital Kuala Lumpur. Med J Malaysia. 2012;67(4): 393-8.

5. Jasa ZK, Jamal F, Hidayat I. Luaran pasien cedera kepala berat yang dilakukan operasi kraniotomi evakuasi hematoma atau kraniektomi dekompresi di RSU Dr. Zainoel Abidin Banda Aceh. JNI. 2014;3(1):8-14.

6. Johans SJ, Garst JR, Burkett DJ, Grahnke K, Martin B, Ibrahim TF, et al. Identification of preoperative and intraoperative risk factor for complications in the elderly undergoing elective craniotomy. World Neurosurg. 2017;107:216-25.

7. RISKESDAS. Riset Kesehatan Dasar. Badan Penelitian dan Pengembangan Kesehatan. Kementrian Kesehatan Tahun 2013. Jakarta, 2013.

8. Pribadi HT. Angka kematian pasien Kraniotomi di ICU dan HCU RSUP. Dr. Kariadi Periode Februari 2010 sampai Februari 2012 [Skripsi]. Semarang: Fakultas Kedokteran Universitas Diponegoro; 2012.

9. Sodiq MN, Untung A, Purwoko. Profil penggunaan ventilator pada pasien post operasi Kraniotomi E.C. Tumor Cerebri di Rumah Sakit Dr. Moewardi (RSDM) Surakarta Tahun 2008-2010. Jurnal Medika Moewardi. 2013;2(2):6-12.

10. Souter MJ, Manno EM. Ventilatory management and extubation criteria of the neurological/neurosurgical patient. Neurohospitalist. 2013;3(1):39-45.

11. Lalenoh DC, Lalenoh HJ, Rehata NM. Anestesia untuk Kraniotomi Tumor Supratentorial. JNI. 2012;1(1):16-24.

12. Zwingly P, Oley MC, Limpeleh HP. Gambaran kualitas hidup pasien cedera kepala pasca operasi periode januari 2012 - desember 2013 di RSUP Prof. Dr. R. D. Kandou Manado. eCl. 2015;3(1):153-7.

13. Adigun TA, Adeolu AA, Adeleye AO, Shokunbi MT, Malomo AO, Boadu SD. Anesthetic and surgical predictors of treatment outcome in Re-Do Craniotomy. J Neurosci Rural Pract. 2011;2(2):137-40. 